\title{
Gemcitabine-Cisplatin Regimen
}

National Cancer Institute

\section{Source}

National Cancer Institute. Gemcitabine-Cisplatin Regimen. NCI Thesaurus. Code C63406.

A chemotherapy regimen consisting of gemcitabine hydrochloride and cisplatin used in the treatment of a variety of cancers, including bladder, cervical, pancreatic, ovarian, mesothelioma, and non-small cell lung cancer (NSCLC). 